\title{
Fluid Dynamic Bearings: Modelling of Elastic Deformations
}

\author{
Viktor A. Ivanov ${ }^{\mathrm{a}^{*}}$, \\ Nikolai V. Erkaeva,b and Daniel Langmayr ${ }^{\mathrm{c}}$ \\ ${ }^{a}$ Siberian Federal University \\ 79 Svobodny, Krasnoyarsk, 660041, Russia \\ ${ }^{b}$ Institute of Computational Modelling SB RAS \\ 50/44 Akademgorodok, Krasnoyarsk, 660036, Russia \\ ${ }^{c}$ ANSYS Germany GmbH \\ Staudenfeldweg 12, Otterfing, 83624, Germany
}

Received 02.03.2015, received in revised form 27.03.2015, accepted 07.04.2015

This article deals with a new approach for calculation of self-consistent pressure distribution and surface deflection for a lubricated journal bearing. This approach is based on the numerical solution of the 2-D Reynolds' equation for the lubrication layer, numerical calculation of the surface deformations by the 3-D ANSYS package and Fourier series expansion for the compliance matrix. A simple analytical approximation is found for the obtained compliance matrix, which can be used for heavy loaded journal bearings. The compliance matrix is implemented into the iterative procedure for calculation of self-consistent pressure distribution and surface deflection in the contact zone. Results of calculations are presented for the particular journal bearing.

Keywords: journal bearing, elastic hydrodynamics, compliance matrix.

(C) Siberian Federal University. All rights reserved

* Corresponding author E-mail address: Vintextrim@yandex.ru 


\title{
Гидродинамический подшипник скольжения:
} моделирование упругих деформаций

\author{
В.А. Иванов ${ }^{\mathrm{a}}$, Н.В. Еркаев ${ }^{\mathrm{a}, \boldsymbol{\sigma}}$, Д. Лангмайр ${ }^{\text {в }}$ \\ ${ }^{a}$ Сибирский федеральный университет \\ Россия, 660041, Красноярск, пр. Свободный, 79 \\ ${ }^{6}$ Институт вычислительного моделирования СО РАН \\ Россия, 660036, Красноярск, Академгородок, 50/44 \\ ${ }^{6}$ Германский филиал фирмы АНСИС \\ Германия, 83624, Оттерфинг, Штауденфельдвег, 12
}

\begin{abstract}
В статье рассмотрен новый подход к вычислению самосогласованного распределения давления и деформации поверхности для ичилиндрического подиипника скольжения. Предлагаемый метод основан на численном решении 2-мерного уравнения Рейнольдса для смазочного слоя, вычислении деформации поверхности с помощью 3-мерного пакета АНСИС с использованием разложения Фурье для вычисления матрицы податливости. Найдена простая аналитическая аппроксимация для матрицы податливости, которая может применяться для расчета тяжело нагруженных подшипников скольжения. Найденная матрииа податливости используется в итеративной процедуре для расчета самосогласованного распределения давления и прогиба поверхности в зоне контакта. Представлены результаты расчета конкретного подшипника скольжения.
\end{abstract}

Ключевые слова: подшипник скольжения, упругогидродинамический контакт, матрица податливости.

\section{Introduction}

Hydrodynamic lubrication theory is a commonly used tool for calculating and designing fluid dynamic journal bearings, which are important parts of various mechanisms and vehicles. There exist many publications devoted to this subject $[1-4]$. The role of elastic deformations becomes very important for heavy loaded journal bearings. Therefore elastic effects were incorporated into the lubrication theory, and the so called elastic hydrodynamic approach was developed, which considers both lubricant flow and surface deformations caused by enhanced pressure in the lubricant film [5]. In this approach, a key problem is to find a relationship between lubricant pressure distributions and surface deformations. The main constructive elements of a fluid dynamic bearing are shaft (journal), lubricant film, sleeve and housing. Usually housing material is more rigid compared to that of a sleeve. This is the reason why deformations of the housing are often neglected, and the sleeve deformations are used to be taken into account [6]. In such simplified case, the deformations of the thin sleeve constrained by the rigid housing are dependent on a small parameter, which is a ratio of the sleeve thickness to the curvature radius. As shown in [7], in the first order approximation with respect to the small parameter, the sleeve deformation is proportional to the local pressure in the lubricant film. The coefficient of proportionality is called as "sleeve compliance". This approximation is related to the hypothesis of Winkler. In case of cylindrical symmetry, the compliance coefficient can be determined from the analytical solution [8].

Generally, it is necessary to take into account not only sleeve deformations, but also housing deformations, because housing has a finite rigidity. In such a case, calculations of surface deformations 
have to be performed self-consistently with calculations of pressure distributions along the whole lubrication layer. For this purpose we have to determine a generalized equation for relationship between the local surface deformations and the lubricant pressure distributions, taking into account different material properties of the sleeve and housing. The main goal of this work is to elaborate a method for deriving such an equation, and to apply it for self-consistent solution of the elastic hydrodynamic problem.

\section{Satement of problem}

To describe our approach we consider the journal bearing with steel shaft and bronze sleeve shown in Fig. 1. Here $\omega$ is the angular speed of the shaft, $\varphi$ is the azimuthal angle counted clockwise off the maximal clearance, and $\eta$ is the eccentricity of the shaft, $R_{0}$ is the journal radius, $R_{1}$ is the internal radius of the sleeve, $R_{2}$ and $R_{3}$ are the internal and external radii of the steel housing, $L$ is the length of the bearing. We assume that the external boundary of the housing is fixed. This means that deformations vanish at the external boundary of the housing. The shaft and sleeve surfaces are assumed to be separated by a thin film of a liquid lubricant, so called the lubrication layer. We also set zero boundary condition for the pressure at the edges of the bearing.

The pressure distribution in the lubrication layer is determined by the conventional Reynolds' equation [2]

$$
\begin{aligned}
& \frac{1}{R_{0}^{2}} \frac{\partial}{\partial \varphi}\left(\frac{h^{3}}{12 \mu} \frac{\partial P}{\partial \varphi}\right)+\frac{\partial}{\partial y}\left(\frac{h^{3}}{12 \mu} \frac{\partial P}{\partial y}\right)=\frac{1}{R_{0}} \frac{\partial h u}{\partial \varphi}, \\
& h=R_{1}-R_{0}+\eta \cos (\varphi)+\delta(P), \quad P>0 ; \\
& \frac{\partial h u}{\partial \varphi}=0, \quad P \leq 0 .
\end{aligned}
$$

Here $h$ is the thickness of the lubrication layer, $\mu$ is the viscosity coefficient, $u$ is the mean velocity of the boundary surfaces, $y$ is the coordinate along the axis of the journal bearing, $\varphi$ is the

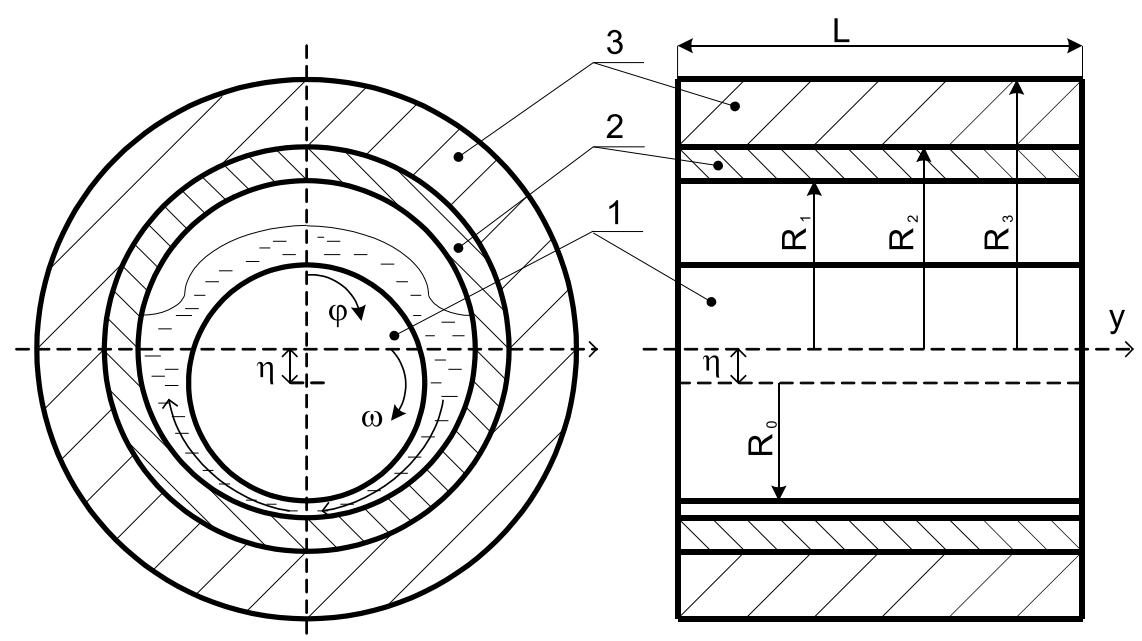

Fig. 1. Geometrical scheme of the journal bearing: 1 is the shaft, 2 is the bronze sleeve, 3 is the steel housing 
azimuthal angle, $\delta$ is the radial deflection of the sleeve surface, which is dependent on the pressure in the lubrication layer.

For computational convenience we introduce normalized parameters as follows:

$$
\begin{aligned}
& P=\widetilde{P} \frac{6 \mu R_{1}^{2} \omega}{d^{2}}, \quad h=H d, \quad d=R_{1}-R_{0} \\
& y=R_{1} \widetilde{y}_{1}, \quad u=\omega R_{1} / 2, \quad \eta=\widetilde{\eta} d
\end{aligned}
$$

where $\widetilde{P}$ is the dimensionless pressure, $\tilde{y}$ is the dimensionless coordinate along the rotational axis, and $H$ is the dimensionless thickness of the lubrication layer. With normalizations (4) we transform the Reynolds' equation to the dimensionless form and add a relaxation parameter $\alpha$

$$
\begin{aligned}
& \frac{\partial}{\partial \varphi}\left(H^{3} \frac{\partial \widetilde{P}}{\partial \varphi}\right)+\frac{\partial}{\partial \widetilde{y}}\left(H^{3} \frac{\partial \widetilde{P}}{\partial \widetilde{y}}\right)=\frac{\partial H}{\partial \varphi}+\alpha \frac{\partial \widetilde{P}}{\partial t}, \\
& H=1-\widetilde{\eta} \cos (\varphi)+\widetilde{\delta}(\widetilde{P}), \quad \widetilde{P}>0 ; \\
& \frac{\partial H}{\partial \varphi}=0, \quad \widetilde{P} \leq 0 .
\end{aligned}
$$

There are many publications devoted to numerical methods for integration of the Reynolds' equation [9-12]. In our case, numerical solution of Eq. (5) is obtained by a relaxation method based on an implicit scheme with the finite difference approximations [13]:

$$
\begin{aligned}
& \frac{1}{\Delta \varphi^{2}}\left[A_{i+1 / 2, j} P_{i+1, j}^{n+1 / 2}-\left(A_{i+1 / 2, j}+A_{i-1 / 2, j}\right) P_{i, j}^{n+1 / 2}+A_{i-1 / 2, j} P_{i-1, j}^{n+1 / 2}\right]+ \\
& \frac{A_{i, j}}{\Delta y^{2}}\left(P_{i, j+1}^{n}-2 P_{i, j}^{n}+P_{i, j-1}^{n}\right)=\frac{H_{i+1}-H_{i-1}}{2 \Delta \varphi}+\alpha \frac{P_{i, j}^{n+1 / 2}-P_{i, j}^{n}}{\Delta t}, \\
& \frac{A_{i, j}}{\Delta y^{2}}\left(P_{i, j+1}^{n+1}-2 P_{i, j}^{n+1}+P_{i, j-1}^{n+1}\right)=\alpha \frac{P_{i, j}^{n+1 / 2}-P_{i, j}^{n}}{\Delta t}+\frac{A_{i, j}}{\Delta y^{2}}\left(P_{i, j+1}^{n}-2 P_{i, j}^{n}+P_{i, j-1}^{n}\right), \\
& A_{i, j}=H_{i, j}^{3}, \quad A_{i+1 / 2, j}=\left(A_{i, j}+A_{i+1, j}\right) / 2, i=1 \ldots N .
\end{aligned}
$$

Here the lower indices $i, j$ enumerate the grid points, and the upper index $n$ enumerates time steps. Eqs. (8) are solved by a tri-diagonal matrix algorithm. A stationary pressure distribution is obtained as a result of time relaxation of the numerical solution.

\section{Results of calculations. 2-d ANSYS model}

For illustrating our method, we take the following input parameters of the journal bearing: $R_{1}=0.03 \mathrm{~m}, R_{2}=0.035 \mathrm{~m}, R_{3}=0.1 \mathrm{~m}, d=0.00013 \mathrm{~m}, E_{1}=2.1 \cdot 10^{11} \mathrm{~Pa}, E_{2}=1.08 \cdot 10^{11} \mathrm{~Pa}, m_{1}=0.3$, $m_{2}=0.34, \mu=0.024 \mathrm{~Pa} / \mathrm{s}, \omega=314.16 \mathrm{~s}^{-1}$, where $E_{1}$ and $E_{2}$ are the elasticity moduluses of the steel housing and bronze sleeve, $m_{1}$ and $m_{2}$ are the Poisson coefficients corresponding to the materials of the housing and sleeve, respectively. The length and diameter of the journal bearing are assumed to be equal to each other. 
Fig. 2 shows pressures in the lubrication layer as functions of the azimuthal angle. These pressures are obtained from the numerical solution of equation (5) for journal eccentricities $\widetilde{\eta}=0,9$ and $\widetilde{\eta}=0,8$. Further, we used these pressure distributions for calculating the elastic deformations of the sleeve and housing. For this purpose we applied the ANSYS package based on the finite element numerical method [14]. Fig. 3 shows mesh spacing of the 2-D calculation domain with 5 elements across the bronze sleeve, 9 elements across the steel housing, and 100 elements along the azimuthal direction. The previously calculated pressures are applied to the grid points at the internal boundary of the sleeve.

Performing 2-D ANSYS calculations for the given pressure distribution along the lubrication layer (Fig. 2), we obtained results presented in Fig. 4. Here the sleeve and housing deformations are

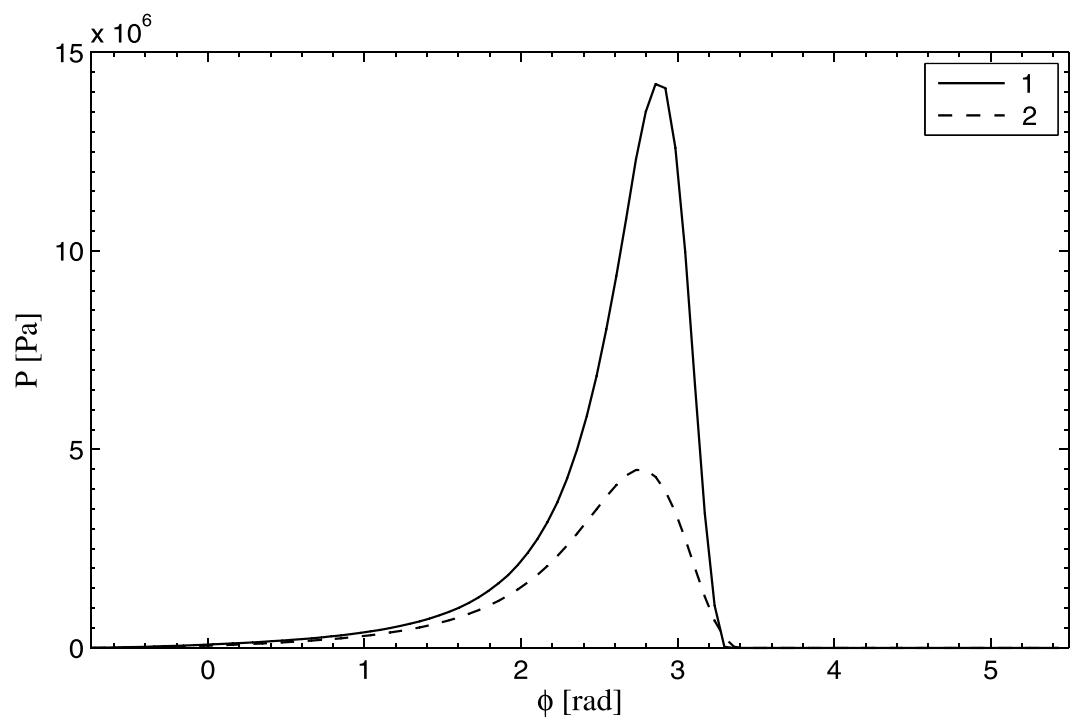

Fig. 2. Distribution of the pressure along the lubrication layer for two eccentricities: 0.9 (curve 1) and 0.8 (curve 2)

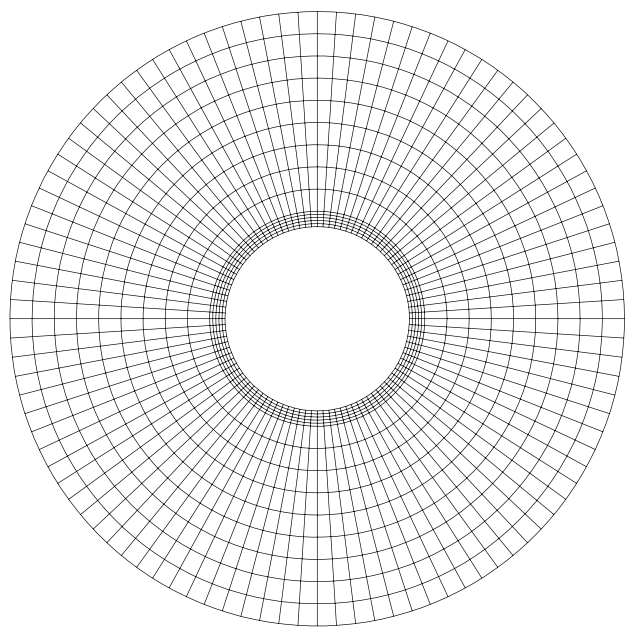

Fig. 3. Mesh spacing of the 2-D ANSYS model 


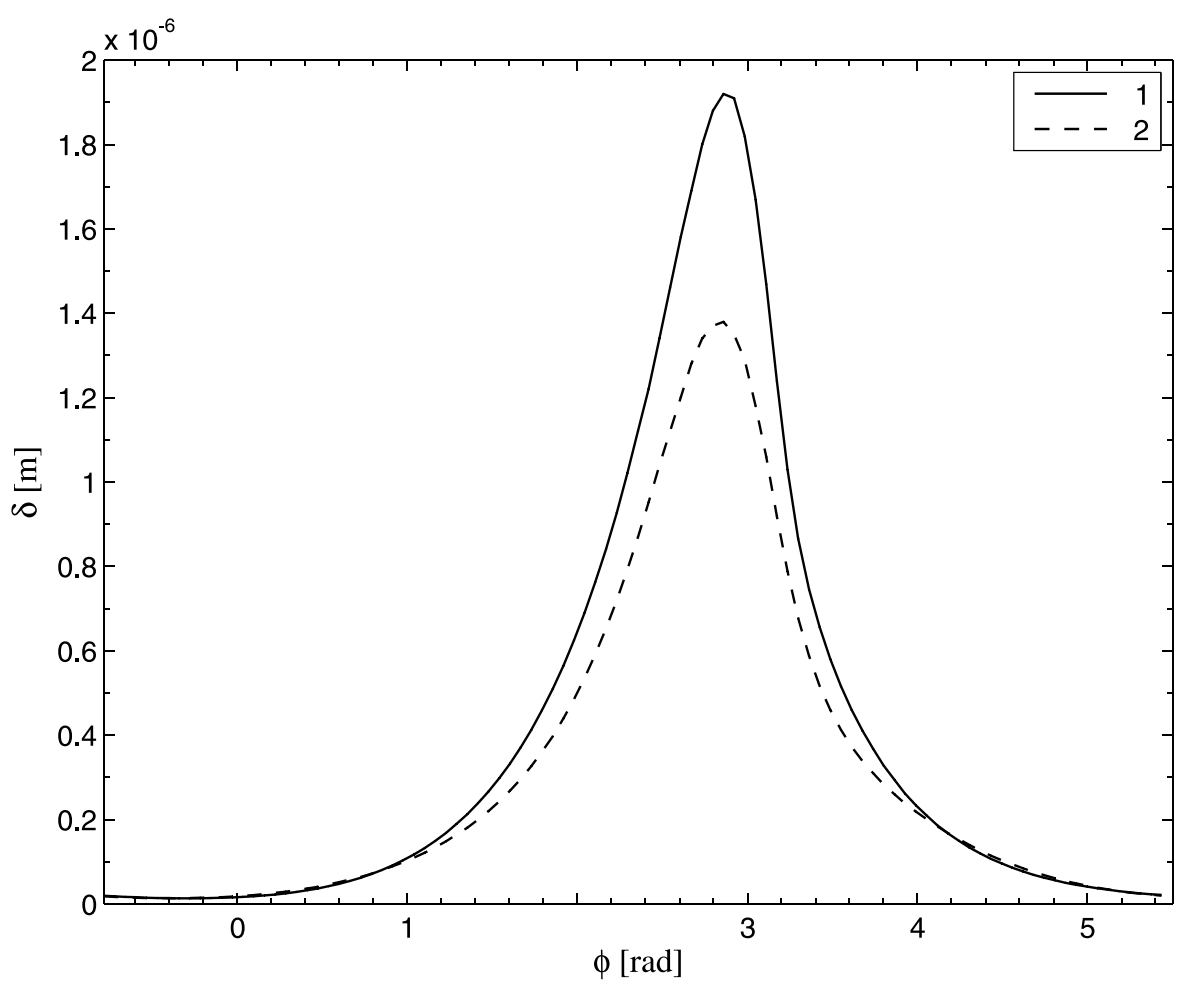

Fig. 4. Deformations of the sleeve (curve 1) and housing (curve 2)

shown by the solid and dashed lines, respectively. These numerical results can be compared to the approximate analytical formula [6] implying a proportional relationship between deformation of a thin sleeve and the corresponding local hydrodynamic pressure in the lubrication film

$$
\delta=D P, D=\frac{\left(R_{2}-R_{1}\right)}{E_{2}} \frac{\left(1+m_{2}\right)\left(1-2 m_{2}\right)}{\left(1-m_{2}\right)} .
$$

This formula implies proportionality of the pressure and deflection, and thus it neglects nonlocal influence of the pressure.

More general and realistic formula describing dependence of elastic deformations on pressure distributions can be written in the integral form:

$$
\delta(\varphi)=\int_{0}^{2 \pi} P\left(\varphi^{\prime}\right) K\left(\varphi-\varphi^{\prime}\right) d \varphi^{\prime}
$$

where $\delta$ and $P$ are the surface deflection and pressure as functions of the azimuthal angle, $K\left(\varphi-\varphi^{\prime}\right)$ is the kernel function, which determines a compliance matrix. This function does not depend on the pressure distribution, but it depends on the geometric characteristics of the journal bearing. It can be determined based on the numerical results described above. For this purpose we apply Fourier series expansion:

$$
K(\varphi)=\sum_{k=0}^{n}\left[M_{k} \cos (k \varphi)+N_{k} \sin (k \varphi)\right]
$$


Multiplying equation (11) on the harmonic functions and integrating over the angle from 0 to $2 \pi$, we obtain a linear algebraic system of equations for the unknown Fourier coefficients $M_{k}$ and $N_{k}$.

$$
\begin{aligned}
& M_{k} \int_{0}^{2 \pi} P\left(\varphi^{\prime}\right) \sin \left(k \varphi^{\prime}\right) d \varphi^{\prime}+N_{k} \int_{0}^{2 \pi} P\left(\varphi^{\prime}\right) \cos \left(k \varphi^{\prime}\right) d \varphi^{\prime}= \\
& =\frac{1}{\pi} \int_{0}^{2 \pi} \delta\left(\varphi^{\prime}\right) \sin \left(k \varphi^{\prime}\right) \cdot d \varphi^{\prime}, k=1,2,3 \ldots \\
& M_{k} \int_{0}^{2 \pi} P\left(\varphi^{\prime}\right) \cos \left(k \varphi^{\prime}\right) d \varphi^{\prime}-N_{k} \int_{0}^{2 \pi} P\left(\varphi^{\prime}\right) \sin \left(k \varphi^{\prime}\right) d \varphi^{\prime}= \\
& =\frac{1}{\pi} \int_{0}^{2 \pi} \delta\left(\varphi^{\prime}\right) \cos \left(k \varphi^{\prime}\right) \cdot d \varphi^{\prime}, k=1,2,3 \ldots \\
& M_{0} \int_{0}^{2 \pi} P\left(\varphi^{\prime}\right) d \varphi^{\prime}=\frac{1}{2 \pi} \int_{0}^{2 \pi} \delta\left(\varphi^{\prime}\right) d \varphi^{\prime}
\end{aligned}
$$

Using the known distribution of pressure in the lubrication layer and surface deformations calculated by ANSYS we find the solution of linear equations $(12,13)$

$$
\begin{aligned}
& M_{k}=\frac{1}{\pi} \frac{X_{k} C_{k}+Y_{k} D_{k}}{X_{k}^{2}+Y_{k}^{2}}, \quad N_{k}=\frac{1}{\pi} \frac{Y_{k} C_{k}-X_{k} D_{k}}{X_{k}^{2}+Y_{k}^{2}}, \quad k=1,2,3 \ldots \\
& M_{0}=\frac{D_{0}}{2 \pi Y_{0}}
\end{aligned}
$$

where

$$
\begin{aligned}
X_{k} & =\int_{0}^{2 \pi} P\left(\varphi^{\prime}\right) \sin \left(k \varphi^{\prime}\right) \cdot d \varphi^{\prime}, & Y_{k} & =\int_{0}^{2 \pi} P\left(\varphi^{\prime}\right) \cos \left(k \varphi^{\prime}\right) \cdot d \varphi^{\prime}, \\
C_{k} & =\int_{0}^{2 \pi} \delta\left(\varphi^{\prime}\right) \sin \left(k \varphi^{\prime}\right) \cdot d \varphi^{\prime}, & D_{k} & =\int_{0}^{2 \pi} \delta\left(\varphi^{\prime}\right) \cos \left(k \varphi^{\prime}\right) \cdot d \varphi^{\prime},
\end{aligned}
$$

Here, the pressure and surface deflection as functions of the angle were determined by spline approximation of the grid values $P_{i}$ and $\delta_{i}$. Substituting Fourier coefficients $M_{k}$ and $N_{k}(15,16)$ in Eq. (11) we find

$$
\begin{aligned}
& K\left(\varphi-\varphi^{\prime}\right)=\frac{D_{0}}{2 \pi Y_{0}}+\frac{1}{\pi} \sum_{k=1}^{k=n} \frac{X_{k} C_{k}+Y_{k} D_{k}}{X_{k}^{2}+Y_{k}^{2}} \cos \left(k\left(\varphi-\varphi^{\prime}\right)\right)+ \\
& +\frac{1}{\pi} \sum_{k=1}^{k=n} \frac{Y_{k} C_{k}-X_{k} D_{k}}{X_{k}^{2}+Y_{k}^{2}} \sin \left(k\left(\varphi-\varphi^{\prime}\right)\right) .
\end{aligned}
$$

Here, the accuracy of the result is dependent on a choice of the upper limit of summing $n$. In particular, a value of $n=10$ is quite sufficient for good accuracy of the approximation. Regarding formula (18), it is worth noting about an influence of a small scaled noise, which usually appears in the input data obtained from the numerical calculations. In order to remove effects of such noise, it is necessary to apply some kind of regularization. A general theory of regularizations for integral equations is described in monographs $[15,16]$. To suppress the noisy oscillations, we introduce multiplication 
factors $g_{k}=1 /\left(1+\varepsilon k^{4}\right)$ for the Fourier coefficients (15). Here $\varepsilon$ is a small parameter which has strong influence on damping of the noisy oscillations. With the regularization factors, equations (15) are modified as follows

$$
\tilde{M}_{k}=\frac{g_{k}}{\pi} \frac{X_{k} C_{k}+Y_{k} D_{k}}{X_{k}^{2}+Y_{k}^{2}}, \quad \tilde{N}_{k}=\frac{g_{k}}{\pi} \frac{Y_{k} C_{k}-X_{k} D_{k}}{X_{k}^{2}+Y_{k}^{2}}, \quad k=1,2,3 \ldots
$$

Substituting the modified Fourier coefficients (19) into formula (11) one can obtain the smoothed kernel function:

$$
\begin{aligned}
& \widetilde{K}\left(\varphi-\varphi^{\prime}\right)=\frac{D_{0}}{2 \pi Y_{0}}+\frac{1}{\pi} \sum_{k=1}^{k=n} g_{k} \frac{X_{k} C_{k}+Y_{k} D_{k}}{X_{k}^{2}+Y_{k}^{2}} \cos \left(k\left(\varphi-\varphi^{\prime}\right)\right)+ \\
& +\frac{1}{\pi} \sum_{k=1}^{k=n} g_{k} \frac{Y_{k} C_{k}-X_{k} D_{k}}{X_{k}^{2}+Y_{k}^{2}} \sin \left(k\left(\varphi-\varphi^{\prime}\right)\right) .
\end{aligned}
$$

Increase of the parameter $\varepsilon$ leads to stronger damping of the noise, and it also causes a slight decrease of the kernel function peak. Fig. 5 shows the kernel function (solid line) corresponding to $\varepsilon=0.0001$. In the same figure, the dashed line is the analytical approximation given by simple formula

$$
K_{a n}(\varphi)=1.2 K_{0}\left[\frac{1}{1+a \varphi^{\alpha}}\right]^{\beta},
$$

where $a=5, \alpha=1.7, \beta=1.4$,

$$
K_{0}=\left[\frac{\left(R_{2}-R_{1}\right)}{E_{1}} \frac{\left(1+m_{1}\right)\left(1-2 m_{1}\right)}{1-m_{1}}+\frac{\left(R_{3}-R_{2}\right)}{E_{2}} \frac{\left(1+m_{2}\right)\left(1-2 m_{2}\right)}{1-m_{2}}\right],
$$

The obtained functions (21) and (22) determine the compliance matrix for any distribution of the pressure in the lubrication layer for a given geometric characteristics of the journal bearing. For

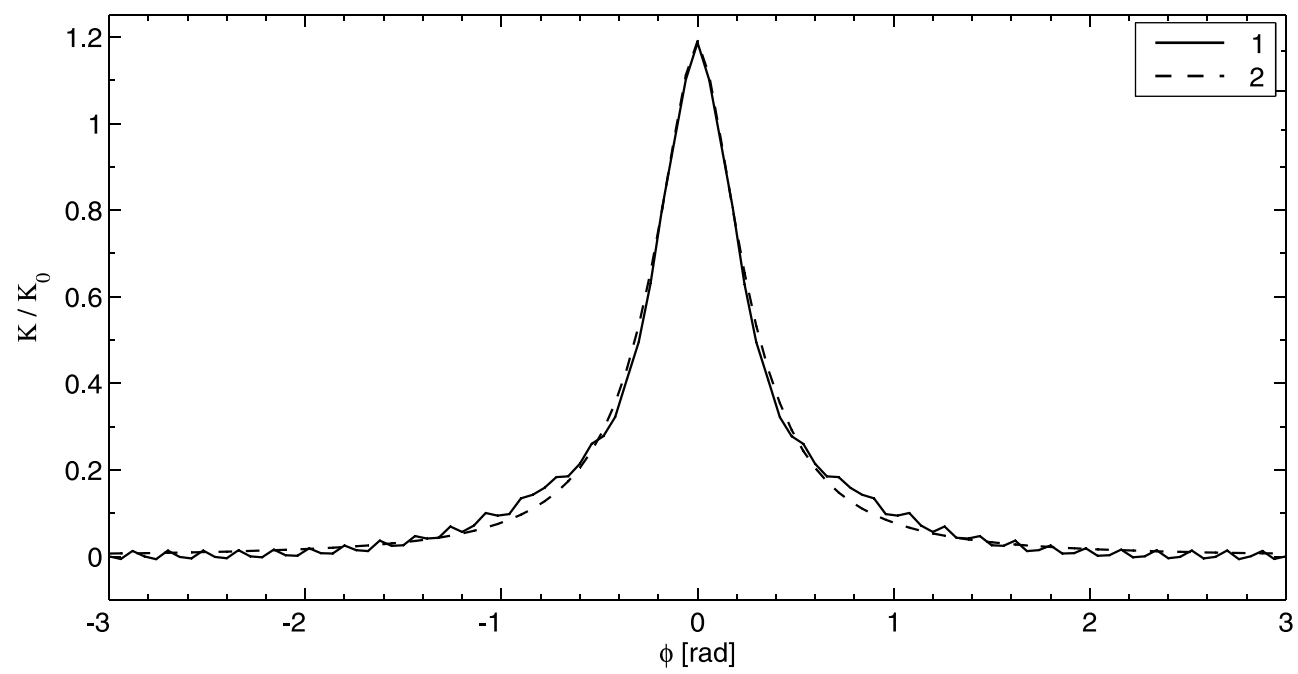

Fig. 5. Kernel function obtained from numerical solution (curve 1) is compared to the analytical approximation (curve 2) given by formula (21) 


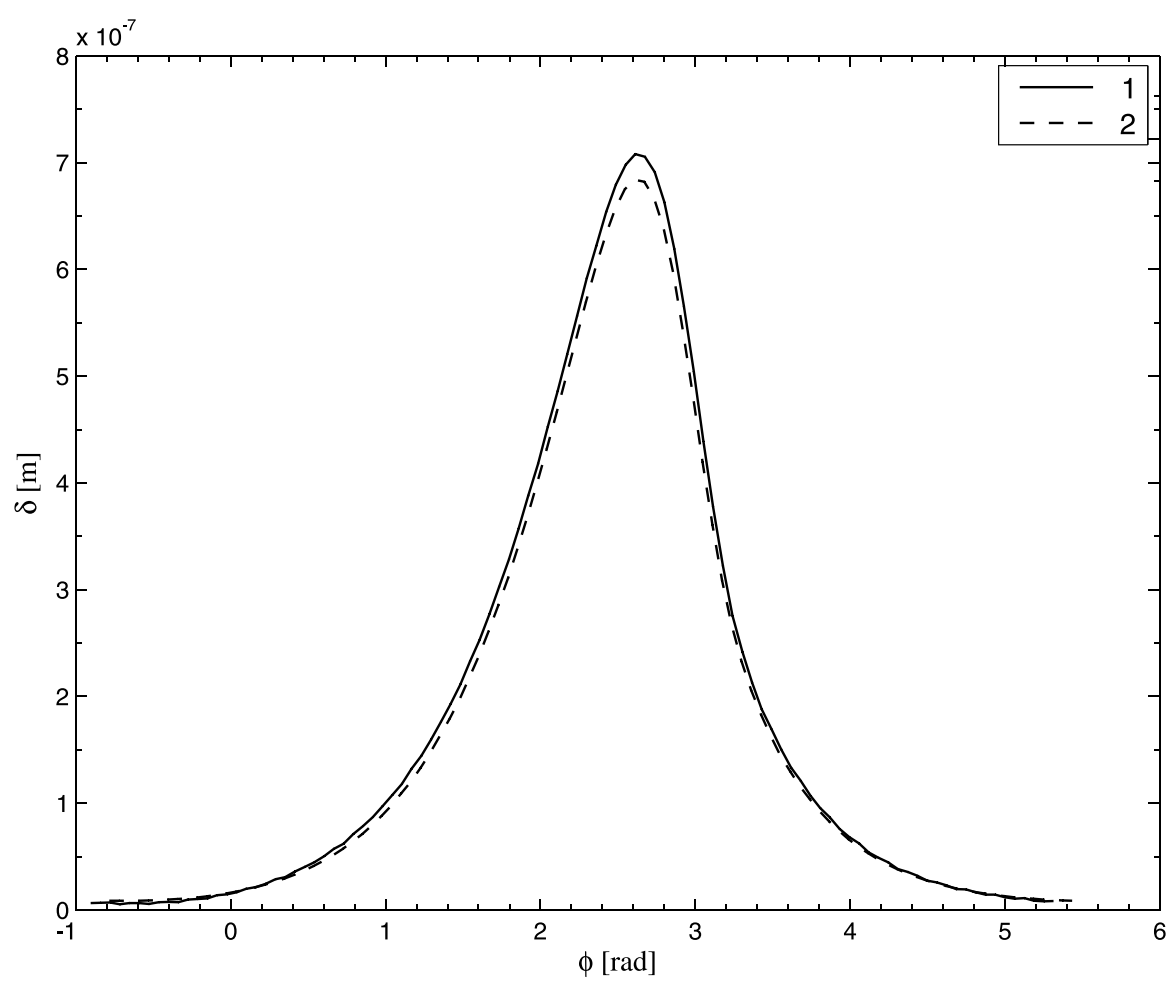

Fig. 6. Curve 1 shows the sleeve deflection obtained from formula (10); and curve 2 is the sleeve deflection calculated by the ANSYS package

testing formula (10), we calculated deformations of the bearing surface related to another pressure distribution (Fig. 2b) corresponding to larger eccentricity $\eta / d=0.8$. These calculations were performed with the ANSYS package. Results of the calculations are shown in Fig. 6. One can see in this figure that formula (10) with $K$ given by (20) yields result (solid line), which is rather close to that of the direct ANSYS calculation (dashed line). A small difference (about $3 \%$ ) can be related to the effects of numerical approximation of the code.

\section{3-d ANSYS calculation}

Next, we analyze a difference between the kernel functions determined for different cross sections of the journal bearing. For this study we use 3-D ANSYS calculations, taking the same parameters of the journal bearing as described above. To determine the deformation caused by the pressure distribution we apply the 3-D ANSYS package with the mesh spacing shown in Fig. 7. Using the finite difference scheme described above, we calculate the hydrodynamic pressure in the lubrication layer as a function of two coordinates in case of journal bearing with finite length. Fig. 8 shows the pressure profiles for different cross sections $(y=$ const) of the bearing. Using results of ANSYS calculations we find deformations of the bearing surface in each cross section. Then we compare the 3-D ANSYS solutions for the central cross section with the 2-D ANSYS solution. Both solutions are presented in Fig. 9. As one can see in Fig. 9, the bearing surface deformation is larger in 2-D case than that in 3-D case. The difference is about $28 \%$. Then we consider the behavior of the kernel functions which determine the 


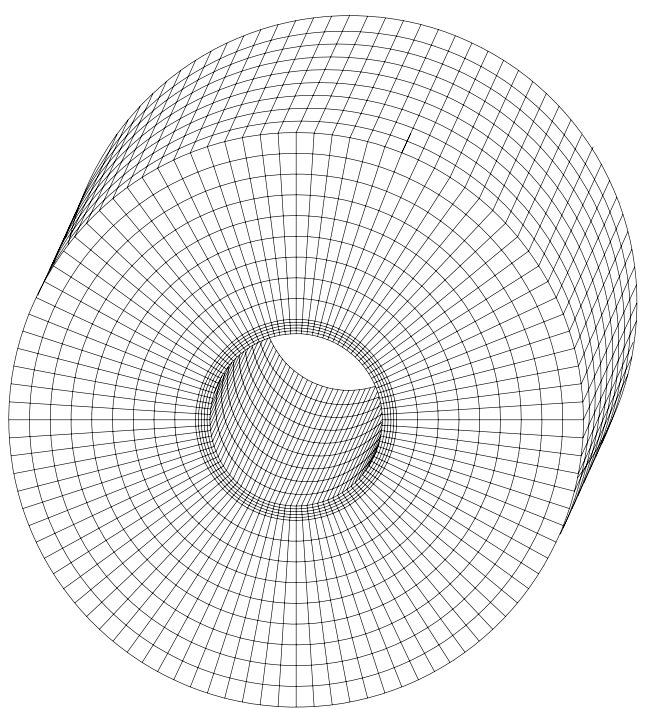

Fig. 7. Mesh spacing for the 3-D ANSYS model

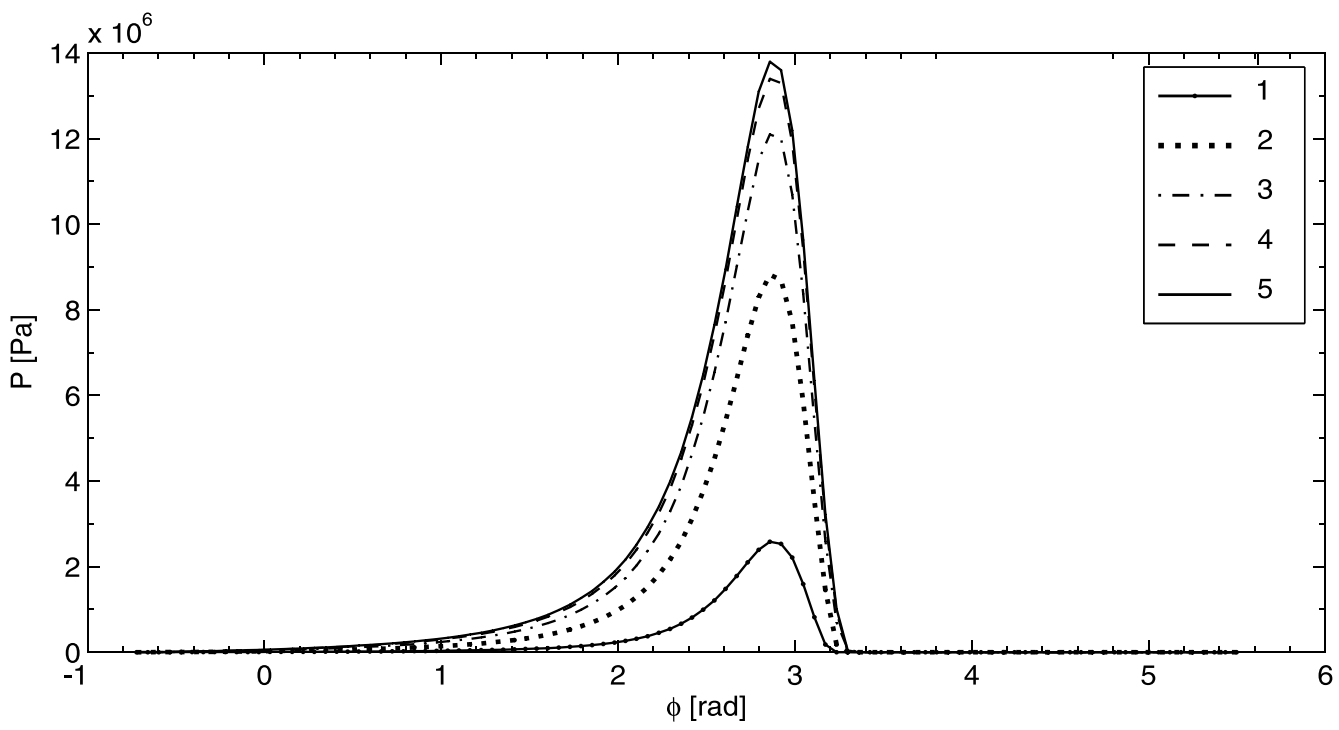

Fig. 8. Azimuthal distributions of the pressure corresponding to the different cross sections of the journal bearing. Curve 1 is for the cross sections close to the edges of the bearing: $y=0.02666 \mathrm{~m}$. Curves 2, 3, 4, and 5 correspond to the cross sections $\mathrm{y}=0.01999 \mathrm{~m}, \mathrm{y}=0.01333 \mathrm{~m}, \mathrm{y}=0.00666 \mathrm{~m}$ and $\mathrm{y}=0$, respectively

compliance matrix for different cross sections. To obtain these functions we used the described above Fourier method, which was applied for different cross sections of the bearing. Finally we find the kernel functions shown in Fig. 10. This figure indicates clearly that the kernel functions are rather close to each other for all cross sections (besides the cross sections near by the edges). Therefore one can use the compliance matrix determined for the central cross section. The kernel function corresponding to 2 -D case is about $28 \%$ larger than that for 3-D case when the length of the bearing is of the same order as its diameter. 


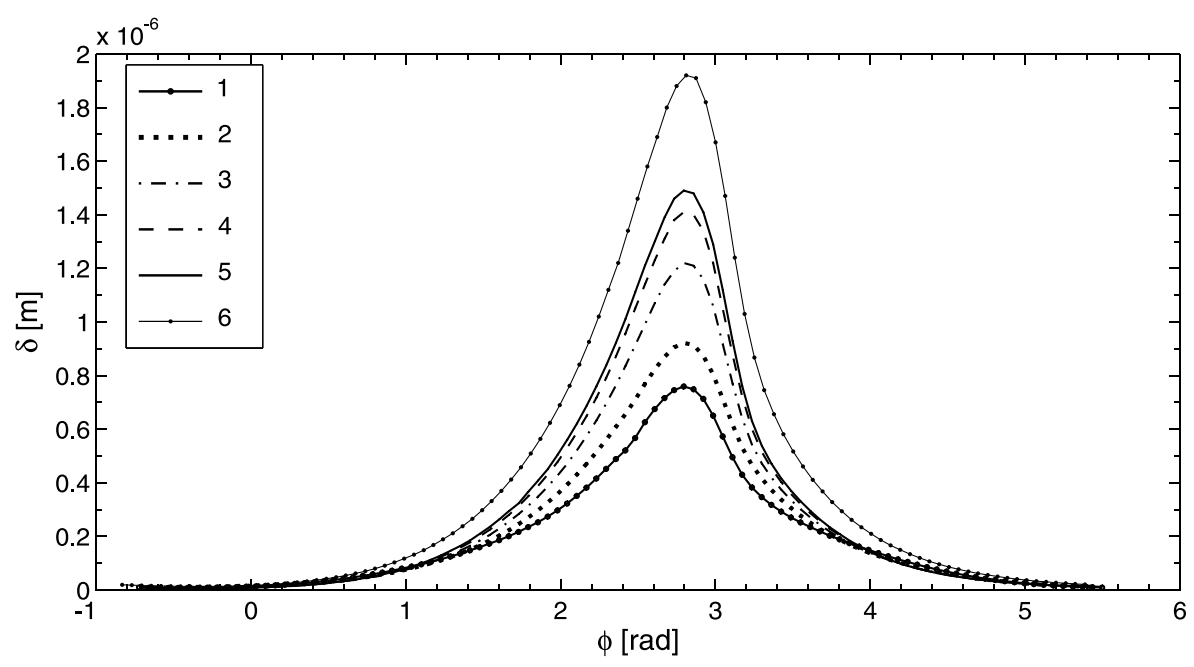

Fig. 9. Deformations of the bearing surface for the different cross sections (3-D model) and also for the 2-D model. Curves 1, 2, 3, 4 and 5 correspond to the surface deflections obtained from the 3-D ANSYS model for the cross sections $\mathrm{y}=0.03 \mathrm{~m}, \mathrm{y}=0.02333 \mathrm{~m}, \mathrm{y}=0.01666 \mathrm{~m}, \mathrm{y}=0.00999 \mathrm{~m}$ and $\mathrm{y}=0.00333 \mathrm{~m}$, respectively; curve 6 is related to the 2-D ANSYS model

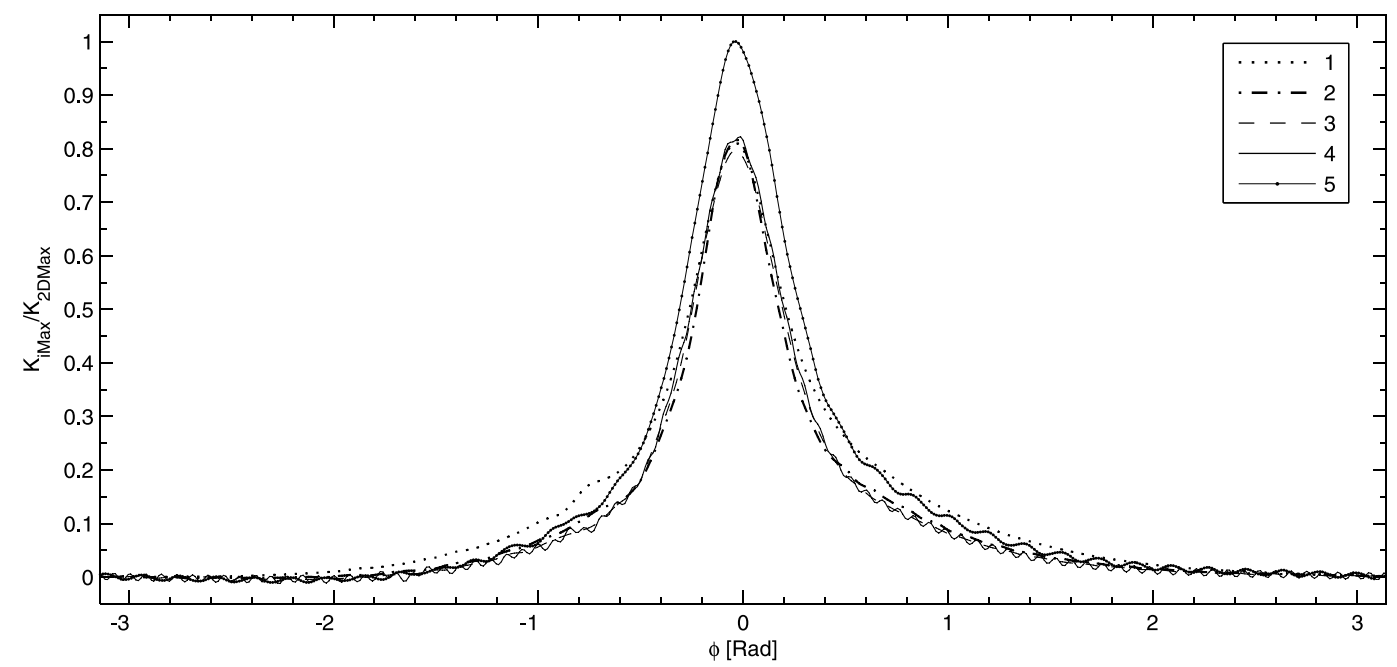

Fig. 10. Kernel functions based on the 3-D and 2-D ANSYS models respectively. Curves 1, 2, 3, 4 correspond to the cross sections $\mathrm{y}=0.02333 \mathrm{~m}, \mathrm{y}=0.01666 \mathrm{~m}, \mathrm{y}=0.00999 \mathrm{~m}$ and $\mathrm{y}=0.00333 \mathrm{~m}$, respectively. Curve 5 is the $2-\mathrm{D}$ kernel function

\section{Self-consistent solution}

We apply the obtained kernel function for self-consistent calculation of the lubrication pressure.

The iterative procedure is as follows:

$$
\frac{\partial}{\partial \varphi}\left[\left(H^{(n)}\right)^{3} \frac{\partial \widetilde{P}^{(n+1)}}{\partial \varphi}\right]+\frac{\partial}{\partial \widetilde{y}}\left[\left(H^{(n)}\right)^{3} \frac{\partial \widetilde{P}^{(n+1)}}{\partial \widetilde{y}}\right]=\frac{\partial H^{(n)}}{\partial \varphi}+\alpha \frac{\left(\widetilde{P}^{(n+1)}-\widetilde{P}^{(n)}\right)}{\Delta t},
$$




$$
\begin{aligned}
& H^{(n)}=1-\widetilde{\eta} \cos (\varphi)+A \int_{0}^{2 \pi} \widetilde{P}^{(n)}\left(\varphi^{\prime}\right) \widetilde{K}\left(\varphi-\varphi^{\prime}\right) d \varphi, \quad \widetilde{P}^{(n)}>0 \\
& \frac{\partial H^{(n)}}{\partial \varphi}=0, \widetilde{P}^{(n)} \leq 0
\end{aligned}
$$

where $A=6 K_{0} \mu R_{1}^{2} \omega / d^{3}$.

This dimensionless parameter $A$ characterizes the role of the elastic surface deformations. Numerical iterations (23) converge to self consistent distributions of the pressure and surface deflection. Those are presented in Fig. 11 for the central cross section $(y=0)$, for three different eccentricities of the shaft: $\widetilde{\eta}=0.8,0.9,0.95$. In case $\widetilde{\eta}=0.95$, the pressure maximum is affected quite strongly by the elastic surface deformation. In this case, the surface deformation leads to corresponding decrease of the pressure maximum in a factor of 1.5 .

\section{Conclusion}

An effective approach is proposed which allows one to determine the compliance matrix on the base of preliminary calculation of the pressure in the lubrication layer (without elastic deformations) and an ANSYS calculation of the surface deformation. Even for a long journal bearing, one has to apply 3-D ANSYS model, rather than 2-D one, for the calculation of the surface deformations. This is because the 2-D ANSYS model overestimates the surface deflection substantially. The compliance matrix is determined by the kernel function which is expressed via Fourier series expansion. In order to suppress the noisy oscillations, we modify the Fourier coefficients by multiplying them on regularization factors, which cause smoothing of the kernel function. The compliance matrices obtained for different cross sections of the journal bearing are very similar to each other. Therefore it is sufficient to determine the compliance matrix for the central cross section only. The compliance matrix depends on constructive parameters of the journal bearing, but it does not depend on a specific pressure distribution. Therefore obtained once, the compliance matrix can be used iteratively together with the Reynolds equation for self consistent simulations of the dynamical regimes of the journal bearing. The proposed iterative procedure converges rather quickly and thus it is very
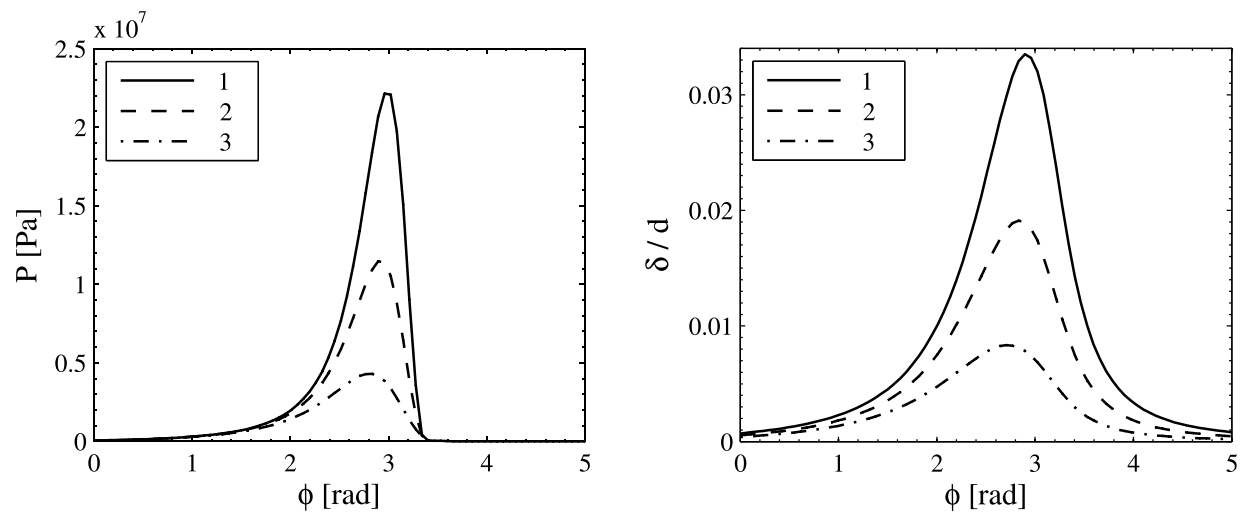

Fig. 11. Self consistent pressure and surface deflection profiles corresponding to the central cross section $(y=0)$ for three eccentricities: 0.95 (curve 1), 0.9 (curve 2) and 0.8 (curve 3). Here $\delta$ is normalized to d $=\mathrm{R} 1-\mathrm{R} 0$ 
efficient for obtaining a self-consistent surface deformations and pressure distribution in heavy loaded journal bearings.

This work was supported by the Russian Foundation for Basic Research (project 15-0500879).

\section{References}

[1] Williams J.A. Engineering tribology. New York: Oxford University Press Inc. 242. 1994.

[2] Hamrock B. J. Fundamentals of fluid film lubrication. McGraw-Hill Inc. 1994.

[3] Bair S. High-Pressure Theology for quantitative elastohydrodynamics. In Tribology and Interface Engineering Series; 54, Elsevier: The Netherlands. 2007.

[4] Szeri A. Z. Fluid film lubrication (2-nd ed.). Cambridge University Press. 2011.

[5] Lugt P. M., Morales-Espejel G. E. A Review of elasto-hydrodynamic lubrication Tteory. Tribology Transactions. 2011. Vol. 54. P. 470-496.

[6] Galakhov M. A., Usov P. P. Differential and integral equations of the mathematical theory of friction. Nauka, Moscow. 1990.

[7] Goryacheva I. G. Contact mechanism in tribology. Kluwer academic pub lishers. 1998.

[8] Landau L. D., Lifshitz E, M. Theory of elasticity. Pergamon Press. 1970.

[9] Arghir, M., Alsayed, A., and Nicolas D. The finite volume solution of the Reynolds equation of lubrication with film discontinuities. International Journal of Mechanical Sciences. 2002. Vol. 44.

[10] Benasciutti D., Gallina M., Munteanu M. A numerical approach for the analysis of deformable journal bearings. Frattura ed Integrit Strutturale. 2012. Vol. 21. P. 37-45.

[11] Salant R.F., Fortier A. E. Numerical Simulation of a slider Bearing with an engineered slip/ no-slip surface. Tribology and lubrication engineering: 14 International Colloquium Tribology. 13-15 Jan. Esslingen, Germany. Technische Akademie Esslingen. 2004. P. 1699-1704.

[12] Kumar M. S., Thyla P. R., Anbarasu E. Numerical analysis of hydrodynamic journal bearing under transient dynamic conditions. MECHANIKA. 2010. Vol. 2(82). P. 37-42.

[13] Samarskii A.A. The theory of difference schemes. USA, Marcel Dekker, Inc. 2001.

[14] Stolarski T., Nakasone Y., Yoshimoto S. Engineering analysis with ANSYS software. ELSEVIER. 2006.

[15] Tikhonov, A. N., Arsenin V. Y. Solution of ill-posed problems. Washington, Winston \& Sons. 1977.

[16] Tikhonov A.N., Goncharsky A.V., Stepanov V.V., Yagola A.G. Numerical methods for the solution of ill-posed problems. Kluwer Academic Publishers. 1995. 